\title{
Knowledge, Behavior and Practices of General Public towards COVID-19 - a study from Islamabad
}

\author{
Asima Mehboob Khan ${ }^{1}$, Rizwan Taj ${ }^{2}$ \\ ${ }^{1}$ Associate Clinical Psychologist, Department of Psychiatry, Pakistan Institute of Medical \\ Sciences, Islamabad, Pakistan \\ ${ }^{2}$ Chairperson, Department of Psychiatry, Pakistan Institute of Medical Sciences, Principal Federal \\ Medical \& Dental College, Islamabad, Pakistan. Chairperson UNESCO Bioethics, Pakistan.
}

Corresponding Author: Rizwan Taj

E-mail: rizwantajpims@gmail.com

\begin{abstract}
Background: The epidemic of the novel Corona virus has become the most difficult pandemic worldwide as so far there is no treatment found. It can be fatal if we do not follow the precautionary guidelines suggested by World Health Organization and Ministry of health. In this context, community needs to have knowledge on this serious health issue and should adopt positive behavior to practice precautions fighting against COVID-19 and protect not only themselves but their loved ones and the society at large. The objective of this investigation was to examine the knowledge, behavior and practices of general public towards novel COVID- 19.

Methodology: 266 persons were enrolled in this cross-sectional study was conducted in various public places of Islamabad from $28^{\text {th }}$ March 2020 till $11^{\text {th }}$ April 2020. A pretested questionnaire by systematic random sampling was administered with basic demographics after taking written informed consent. Individuals were randomly selected and were questioned to know their knowledge, behavior, and practices during the corona virus pandemics.

Results: $42.1 \%$ participants had knowledge of COVID-19 pandemics through electronic and print media while $37.2 \%$ shared that they acquired the knowledge through social media. Majority of the participants reported fever $(23.6 \%)$ and flu $(23.3 \%)$ as the most common symptom of corona virus. $20.67 \%$ respondents acknowledged use of facemask and $19.54 \%$ reported hand washing as a precautionary measure. Majority (22.18\%) of the participants reported that they practicing hand washing regularly and $20.67 \%$ stated that they do wear facemasks. Around $12.4 \%$ of the participants had knowledge about intake of healthy diet and were practicing it as protective measure. Results were computed trough frequencies and percentage.

Conclusion: The crux of the study reveals that knowledge, behavior and practices about novel corona virus infection and its prevention was found to be comprehensive and satisfactory. However, it is still urgent to further strengthen community education on the symptoms and modes of transmission of corona virus infection in all over the country. Our study also depicted that media campaign and talks by the relevant authorities to equip nation with knowledge was an effective strategy in this extraordinary situation.
\end{abstract}

Key words: Knowledge, behavior, practice, covid-19, Islamabad. 


\section{Introduction}

The recent outbreak of novel corona virus has been characterized by the World Health Organization as one of the most challenging pandemic outbreaks of present era. Corona virus infections are respiratory viruses and known to cause illness ranging from the common cold to severe acute respiratory syndrome (SARS) [1].

Corona virus being highly infectious disease, do presents with following symptoms such as flu, fever, cough, fatigue, muscle and body pains. It was reported that $18.5 \%$ of the COVID -19 patients in China, extended to the severe stage, with clinical presentation of acute respiratory distress syndrome, septic shock, difficult-to-tackle metabolic acidosis, and bleeding and coagulation dysfunction [1-3]. The border countries of Pakistan highly affected including China, where the COVID-19 outbreak experienced first time in Wuhan City and became major public health issue [4]. The COVID-19 pandemics have an effect on more than 209 countries. Italy was highly affected with highest number of COVID-19 mortalities while in the north, Iran a high number of mortalities after the Italy [5]. In Pakistan, the first case of COVID-19 has been confirmed by the Ministry of Health, government of Pakistan on February 26, 2020 in Karachi, Sindh province [6-7]. All of the confirmed cases had recent travel history from Iran, Syria and London [8].

In Pakistan to assist epidemic management of COVID-19, there is an urgent need to understand the public's awareness of COVID-19 at this critical moment. In this study, we investigated the knowledge, attitude, behavior and practices towards COVID-19 of general public. The COVID19 is spread by human-to-human through droplets, feco-oral, and direct contact, with an incubation period of 2-14 days [9]. So far, no antiviral treatment or vaccine has been recommended explicitly for COVID-19. Therefore, applying the preventive measure to control COVID-19 infection is the utmost critical intervention [10].

Precautionary measures may include washing hands carefully and regularly with water and soap or any hand washing sanitizer ${ }^{11}$.

Community awareness is very much needed in this regard to adopt protective measures like personal hygiene, social distancing, staying at home and have healthy life style. In this study, we investigated the knowledge, behavior and practices towards COVID-19 of general public. These areas are supposed to mainly influence the degree of devotion to the personal protective measures. Therefore, it is important to study these areas in our population.

\section{Methodology}

A survey was conducted in various main markets of sector F-7, F- 10, I-8 and G-9 from $28^{\text {th }}$ March 2020 till $11^{\text {th }}$ April 2020. Sample was comprised of 266 participants. Random sampling was used to select individuals for interviews. The sample size taken from each sector was as follows: A) 66 from F-7, B) 68 from F-10, C) 66 from I-8, D) 66 from G-9. Standard SOPs were to be followed by both researcher and participant as per WHO and $\mathrm{MOH}$ guidelines. Informed consent was taken from the participants. This study was approved by the Institutional Ethics Committee. Research tools were divided into two parts: Basic demographics, which included variables like gender, age, gender, qualification, employment status and per month income (Table 1). A self-developed comprehensive and well-organized questionnaire which covered the domains of knowledge, behavior and practices related to COVID-19 among common people.

The inclusion criteria were general public, adults of any gender in the main market places of four sectors of Islamabad, 18 years and above age, and at least with primary grade level of education. Only those participants were enrolled and interviewed who has given written consent before participating in the study and fulfilled the inclusion criteria.

The questionnaires included recourse of knowledge about corona virus, knowledge about symptoms, knowledge on precautionary methods and practice of precautionary methods to avoid covid-19 pandemic (Table 2-5). Reponses were recorded as "Yes", "No" and "Not sure". Analyses were performed using frequency and percentages.

\section{Results}

266 participants were enrolled in this study. There were $179(67.29 \%)$ male and $87(32.70 \%)$ females. Majority $(88(33.08 \%))$ of the participants were between $18-28$ years, while only 
$27(10.15 \%)$ were above 60 years of age. About educational qualification, 31 (11.65\%) individuals fall between primary to secondary level, $47(17.66 \%)$ were between metric- F.A, $108(40.60 \%)$ of them were graduated while $80(30.07 \%)$ were Masters or above degree holders. There were $89(33.45 \%)$ individuals in government service, $76(28.57 \%)$ in private services, $55(20.67 \%)$ were doing business, $23(8.64 \%)$ were house wives while same number was either student or unemployed. About monthly income only 22 (8.27\%) reported below Rs.30, 000, 107 (40.22\%) had earning between Rs.31, 000- 50,000, while 137(51.50\%) reported above 50,000 Rs. Sample was taken from four sectors of Islamabad. Basic demographics of the participants have been illustrated in Table 1.

Table 1 - Basic demographic data

\begin{tabular}{|c|c|c|}
\hline Variables & $\mathrm{N}=266$ & \%age \\
\hline Age & & \\
\hline $18-28$ years & 88 & $33.08 \%$ \\
\hline $29-39$ years & 64 & $24.06 \%$ \\
\hline $40-59$ years & 87 & $32.7 \%$ \\
\hline Above 60 years & 27 & $10.15 \%$ \\
\hline \multicolumn{3}{|l|}{ Gender } \\
\hline Male & 179 & $67.29 \%$ \\
\hline Female & 87 & $32.70 \%$ \\
\hline Qualification & & \\
\hline Primary - Middle & 31 & $11.65 \%$ \\
\hline Metric-F.A & 47 & $17.66 \%$ \\
\hline Graduation & 108 & $40.60 \%$ \\
\hline Masters and above & 80 & $30.07 \%$ \\
\hline Occupation & & \\
\hline Government service & 89 & $33.45 \%$ \\
\hline Private service & 76 & $28.57 \%$ \\
\hline Business & 55 & $20.67 \%$ \\
\hline House wife & 23 & $8.64 \%$ \\
\hline Others & 23 & $8.64 \%$ \\
\hline Monthly Income & & \\
\hline Below 30, 000 Rs. & 22 & $8.27 \%$ \\
\hline 31,000 - 50,000 Rs. & 107 & $40.22 \%$ \\
\hline Above 50,000 Rs. & 137 & $51.50 \%$ \\
\hline Sector wise Participants & & \\
\hline F-7 & 66 & $24.81 \%$ \\
\hline F-10 & 68 & $25.56 \%$ \\
\hline $\mathrm{I}-8$ & 66 & $24.81 \%$ \\
\hline G-9 & 66 & $24.81 \%$ \\
\hline
\end{tabular}

Table 2 described the resource of getting knowledge about corona virus infection. $112(42.10 \%)$ reported that they acquired knowledge through both electronic and print media, 99(37.21\%) through social media, $45(16.91 \%)$ through family \& friends and $10(3.75 \%)$ through health professionals. Following responses were identified by the participants on questions about knowledge on common clinical presentation of corona virus infection: $63(23.68 \%)$ fever, $62(23.30 \%)$ flu, $55(20.67 \%)$ cough and difficulty in breathing by $33(12.40 \%)$, sore throat $23(8.64 \%)$ etc. (Table 3$)$. When asked about the precautionary methods for avoiding risk of developing Covid-19, majority of the participants had knowledge of: using facemask 55(20.67\%), $52(19.54 \%)$ hand washing, $28(10.52 \%)$ healthy dietary pattern, $23(8.64 \%)$ staying at home, $22(8.27 \%)$ use of gloves, $21(7.89 \%)$ use of hand sanitizers, social distancing $20(7.51 \%)$, avoiding hand shaking $18(6.76 \%)$, avoiding crowded places $17(6.39 \%)$, and exercise $10(3.75 \%)$ (Table 4$)$. 
Table 5 is about practicing the precautionary methods to stay safe from Covid-19. $59(22.18 \%)$ participants reported that they do practice hand washing regularly, 55(20.67\%) uses facemasks and $35(13.15 \%)$ uses gloves whenever they goes out of home and places where it needed, equal number that is $18(6.76 \%)$ individuals uses sanitizers and maintain social distancing, $14(5.26 \%)$ stated that they do practice staying at home and avoiding leaving the home unnecessarily, on inquiring about avoiding shaking hands and crowded places equal number of participants $11(4.13 \%)$, reported that they are practicing it. $7(2.63 \%)$ do practice avoiding touching their mouth, eyes and nose with hands, only 5 (1.87\%) persons shared that they do practice exercise, although $3.75 \%$ had knowledge about benefits of exercise to avoid risk of covid-19. But majority 33(12.4\%) stated that they do take healthy diet and since heard about benefits of vitamin $\mathrm{c}$ and intake of fluid they consuming it to fight against risk of developing corona virus infection and boost immune system.

Table 2 - Knowledge resource about corona virus

\begin{tabular}{|c|c|c|c|}
\hline No. & Resource & $\mathbf{N = 2 6 6}$ & \%age \\
\hline 1. & Media (both electronic and print) & 112 & $42.10 \%$ \\
\hline 2. & Social Media (Internet, WhatsApp, face book etc.) & 99 & $37.21 \%$ \\
\hline 3. & Family \& friends & 45 & $16.91 \%$ \\
\hline 4. & Health professionals & 10 & $3.75 \%$ \\
\hline
\end{tabular}

Table 3 - Knowledge about COVID-19 symptoms

\begin{tabular}{|c|c|c|c|}
\hline No. & Symptoms & N = 266 & \%age \\
\hline 1. & Flu & 62 & $23.30 \%$ \\
\hline 2. & Cough & 55 & $20.67 \%$ \\
\hline 3. & Sore throat & 23 & $8.64 \%$ \\
\hline 4. & Fever & 63 & $23.68 \%$ \\
\hline 5. & Difficulty in breathing & 33 & $12.40 \%$ \\
\hline 6. & Headache & 10 & $3.75 \%$ \\
\hline 7. & Muscle or joint pains & 11 & $4.13 \%$ \\
\hline 8. & Abdominal Symptoms & 06 & $2.25 \%$ \\
\hline 9. & Dizziness & 03 & $1.12 \%$ \\
\hline
\end{tabular}

Table 4 - Knowledge about COVID-19 precautionary methods

\begin{tabular}{|c|c|c|c|}
\hline No. & Precautionary methods & N = 266 & \%age \\
\hline 1. & Hand washing & 52 & $19.54 \%$ \\
\hline 2. & Use of facemask & 55 & $20.67 \%$ \\
\hline 3. & Use of gloves & 22 & $8.27 \%$ \\
\hline 4. & Use of sanitizers & 21 & $7.89 \%$ \\
\hline 5. & Social distancing & 20 & $7.51 \%$ \\
\hline 6. & Staying at home & 23 & $8.64 \%$ \\
\hline 7. & Avoiding hand shaking/hugging & 18 & $6.76 \%$ \\
\hline 8 & Avoiding crowded places & 17 & $6.39 \%$ \\
\hline 9. & Exercise & 10 & $3.75 \%$ \\
\hline 10. & $\begin{array}{c}\text { Healthy diet/ Use of hot fluids / } \\
\text { Vitamin C containing food etc. }\end{array}$ & 28 & $10.52 \%$ \\
\hline
\end{tabular}


Table 5 - Practice of COVID-19 precautionary methods

\begin{tabular}{|c|c|c|c|}
\hline No. & Precautionary Methods & N= 266 & \%age \\
\hline 1. & Hand washing & 59 & $22.18 \%$ \\
\hline 2. & Use of facemask & 55 & $20.67 \%$ \\
\hline 3. & Use of gloves & 35 & $13.15 \%$ \\
\hline 4. & Use of sanitizers & 18 & $6.76 \%$ \\
\hline 5. & Social distancing & 18 & $6.76 \%$ \\
\hline 6. & Staying at home & 14 & $5.26 \%$ \\
\hline 7. & Avoiding hand shaking/hugging & 11 & $4.13 \%$ \\
\hline 8. & Avoiding touching nose, mouth, eyes & 07 & $2.63 \%$ \\
\hline 9. & Avoiding crowded places & 11 & $4.13 \%$ \\
\hline 10. & Exercise & 05 & $1.87 \%$ \\
\hline 11. & $\begin{array}{c}\text { Healthy diet/ Use of hot fluids / } \\
\text { Vitamin C containing food etc. }\end{array}$ & 33 & $12.4 \%$ \\
\hline
\end{tabular}

\section{Discussion:}

The current study aimed at describing the knowledge, attitudes, and behavior of general public about novel corona virus pandemic and the results could suggest an insight on the approaches necessary to successfully deal with this important subject of community health.

Basic demographics showed that majority of the study participants were male (67.29\%) and 33\% were between 18 years to 28 years of age. Per month income was reported as $51.50 \%$ above 50,000 PKR, 40.22\% had 31,000-50,000PKR, while only $8.27 \%$ were earning below 30,000 PKR.

Our study depicted overall an adequate knowledge, positive attitude and behavior of towards prevention of corona virus. The reason can that study population was taken capital city of Islamabad and from market places located in elite and upper middle to middle class sectors, where majority were literate. A previous study conducted on awareness of knowledge, attitudes, and practices related to EVD prevention and control among the participants also shown same results. It explained that individuals gained key information through the intensified education and mobilization and change in behavior since got knowledge about Ebola [12]. Results of our study reveal that $40.6 \%$ participants were graduated while $30 \%$ were masters and above. Most of them were in government service (33.45\%) as shown in Table 1.

Another study shares the finding of a high correct rate of COVID-19 knowledge in Chinese residents was unexpected, because this epidemiological survey was conducted during the very early stage of the epidemic. Authors considered that this is primarily due to the sample characteristics: $82.4 \%$ of the study sample held an associate's degree or higher. The grave circumstances of the outbreak and the overpowering reports on this community health crisis this population would actively be trained and get knowledge of this infectious disease from a range of information resources. They have found significant positive association between levels of education and COVID-19 knowledge scores supporting this assumption [13].

On inquiring about the resource majority (42.1\%) reported that they got knowledge about corona virus through electronic and print media, $37.2 \%$ through social media, $16.9 \%$ through family and friends while only $3.75 \%$ though health professional. The reason for tele-media or social media being the greater source of knowledge about corona virus is that in this era people are more exposed to these technologies and grabs information from these resources faster (Table 2).

About knowledge on COVID-19 symptoms, most of the participant (23.68\%) reported fever as a symptom of corona virus infection. $23.30 \%$ thought about flu, $20.67 \%$ about cough and $12.40 \%$ about breathing difficulty. $8.64 \%$ said sore throat, $4.13 \%$ muscle pains, $3.75 \%$ headache, $2.25 \%$ abdominal symptoms and only $1.12 \%$ believed in dizziness (Table 3 ). Our results are correlated 
with a previous study conducted in Riyadh which shows that the most common symptom of corona virus is fever (85\%) [14].

About questions on knowledge concerning the precautionary methods against corona virus infection, participants showed satisfactory knowledge as $20.67 \%$ considered facemasks, $19.54 \%$ to hand washing and $8.27 \%$ to use of gloves as a precautionary method. The reason of this knowledge can be the government and media campaigns where it is stressed to adopt such measures for avoiding Covid-19 spread in the community (Table 4).

Majority of the participants $(22.18 \%)$ of our study considered practicing hand washing to be a precaution. $20.67 \%$ reported that they use of facemask as a protective measure. $13.15 \%$ said that they wear gloves as a prevention. Number of participants was similar on practicing use of sanitizer and social distancing (6.76\%). About not using sanitizers, participants shared different views like unavailability or shortage of it, or being an extra expenditure, and few said they do forget using it. Only $5.26 \%$ stated that they mostly practice staying home, while majority was saying that for job or other tasks they cannot stay home. $4.13 \%$ were practicing avoidance of crowded places and shaking hand or hugging, while majority stated that it's our tradition and we are habitual to such practices and its often difficult to avoid when we meet others. Only $2.63 \%$ individuals shared their concern and carefulness about touching nose, eyes and mouth. A lesser number of participants $(1.87 \%)$ were practicing exercise though they considered it important healthy habit. $12.4 \%$ participants were practically using healthy diet as a protection against corona virus infection. They reported that they are aware of the facts that intake of vitamin $\mathrm{c}$ and frequent use of fluid can help fighting against covid-19. Results of a past study is similar to our study in which $85 \%$ participants showed positive behavior towards washing hands and an effective way to prevent coronavirus infection, $81 \%$ use of mask, and $66 \%$ considered wearing gloves to be a preventive method and $21 \%$ avoided fast food as a preventive method [14].

Results of another study reported that there was a frequent use of sanitizers, hand wash, and masks which indicates the increasing concern of participants towards personal hygienic measures to avoid COVID-19 infection. This was reflected in their behavior and attitude significantly as most of the participants (more than 4/5th) agreed with - social distancing, avoiding travel, self-quarantine and adequate hygienic measures [15].

Creating awareness on pandemics protects the community from developing problems other than health like financial or psychological. As our study was conducted in a capital city where majority of the participants were well aware of the outbreak of COVID-19 and its prevention but it is important to create knowledge among people living in remote areas. They need to be educated on personal hygiene and guiding them to avoid touching their mouth, eyes, or picking nose with their hands.

Our study group was well aware and practicing healthy life style which includes balanced diet pattern and exercising for boosting their immunity. As we know there is no treatment found to date to cure corona virus infection and the only source of protection is the precautionary measures, so the general public needs to be well equipped with knowledge to support in decrease the multiplication of the virus. Knowledge, attitudes, and practices can direct people at every corner of the world to adopt healthy and productive lifestyle in prevention of corona virus infection as well as changes in the kinds of practices that need to be followed regarding the prevention of it.

\section{Conclusions}

The crux of the study reveals that knowledge, behavior and practices about novel corona virus infection and its prevention was found to be comprehensive and satisfactory. However, it is still urgent to further strengthen community education on the symptoms and modes of transmission of corona virus infection in all over the country. Our study also depicted that media campaign and talks by the relevant authorities to equip nation with knowledge was an effective strategy in this extraordinary situation.

\section{REFERENCES}

1. Yin Y, Wunderink RG. MERS, SARS and other corona viruses as causes of pneumonia. 
Respirology 2018;23(2):130-7.

2. The Novel Coronavirus Pneumonia Emergency Response Epidemiology Team. The epidemiological characteristics of an outbreak of 2019 novel coronavirus diseases (COVID-19) in China. Chin J Epidemiol 2020;41:145-51.

3. Chen N, Zhou M, Dong X, Qu J, Gong F, Han Y. et al. Epidemiological and clinical characteristics of 99 cases of 2019 novel coronavirus pneumonia in Wuhan, China: a descriptive study. Lancet 2020;395:507-13.

4. Lai CC, Shih TP, Ko WC, Tang HJ, Hsueh PR. Severe acute respiratory syndrome coronavirus 2 (SARS-CoV-2) and corona virus disease-2019 (COVID-19): the epidemic and the challenges. Int J Antimicrob Agent 2020:105924.

5. Saqlain M, Munir MM, Ahmed A, Tahir AH, Kamran S. Is Pakistan prepared to tackle the coronavirus epidemic? Drugs Ther Persp 2020;1:1-12.

6. Ali A. Pakistan confirms first two cases of corona virus, govt says "no need to panic" From https://www.dawn.com/news/amp/15367 92.

7. Geo news: https://www.geo.tv/latest/274482-pakistan-confirms-first Accessed 4th Apr 2020.

8. COVID-19 live dashboard (Pakistan): national institute of health Islamabad. https://www.nih.org.pk/novel-coranavirus-2019-ncov/Accessed 5th April 2020

9. World Health Organization. Novel coronavirus (COVID-19) situation. Available online: https://https://experience.arcgis.com/experience/685d0ace521648f8a5beeeee1b9125cd

10. World Health Organization. Infection prevention and control during health care when novel coronavirus ( $\mathrm{nCoV}$ ) infection is suspected: interim guidance, January 2020. World Health Organization; 2020. Available: https://www.who.int/publications-detail/infection-preventionand-control-during-health-care-when-novel-coronavirus-(ncov)-infection-is-suspected-20200125 (Accessed on 12 February 2020).

11. Deng X, Stjohn SE, Osswald HL, O' Brien A, Banach BS. Coronaviruses resistant to a 3C-like protease inhibitorare attenuated for replication and pathogenesis revealing a low genetic barrier but high fitness cost of resistence. J Virol 2014;88(20):11886-98.

12. Kobayashi M, Beer KD, Bjork A, Chatham-Stephens K, Cherry CC, Arzoaquoi S, Frank W, Kumeh O, Sieka J, Yeiah A, Painter JE, Yoder JS, Flannery B, Mahoney F, Nyenswah TG. Community Knowledge, Attitudes, and Practices Regarding Ebola Virus Disease - Five Counties, Liberia, September-October, 2014. MMWR Morb Mortal Wkly Rep 2015;64(26):714-8.

13. Zhong BL, Luo W, Li HM, Zhang QQ, Liu XG, Li WT, Li Y. Knowledge, attitudes, and practices towards COVID-19 among Chinese residents during the rapid rise period of the COVID-19 outbreak: a quick online cross-sectional survey. Int J Biol Sci 2020;16(10):1745-52.

14. Alsharyoufi M. Public Awareness about Corona Virus for KAMC Visitors in Riyadh. J Commun Med. 2016;2(1):17.

15. Roy D, Tripathy S, Kar SK, Sharma N, Verma SK, Kaushal V. Study of knowledge, attitude, anxiety \& perceived mental healthcare need in Indian population during COVID-19 pandemic. Asian J Psychiatry 2020;51:102083.

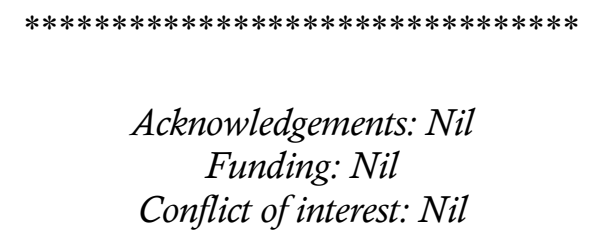

